\title{
Effect of Geometrical Parameters on Optimal Design of Synchronous Reluctance Motor
}

\author{
V. S. Nagarajan ${ }^{1 *}$, V. Kamaraj ${ }^{1}$, M. Balaji ${ }^{1}$, R. Arumugam ${ }^{1}$, N. Ganesh ${ }^{2}$, R. Rahul ${ }^{1}$, and M. Lohit ${ }^{3}$ \\ ${ }^{1}$ Electrical and Electronics Engineering, SSN College of Engineering, Old Mahabalipuram Road, Kalavakkam, \\ Tamil Nadu 603110, India \\ ${ }^{2}$ Renault-Nissan Technology and Business Centre India Private Ltd, Ascendas IT Park, Mahindra World City SEZ, Plot no TP2/1 \\ Natham Phase I \& 2, Ground Floor, Chennai,, Chengalpattu, Tamil Nadu 603002, India \\ ${ }^{3}$ Mechanical Engineering, SSN College of Engineering, Old Mahabalipuram Road, Kalavakkam, Tamil Nadu 603110, India
}

(Received 29 July 2016, Received in final form 17 October 2016, Accepted 18 October 2016)

\begin{abstract}
Torque ripple minimization without decrease in average torque is a vital attribute in the design of Synchronous Reluctance (SynRel) motor. As the design of SynRel motor is an arduous task, which encompasses many design variables, this work first analyses the significance of the effect of varying the geometrical parameters on average torque and torque ripple and then proposes an extensive optimization procedure to obtain configurations with improved average torque and minimized torque ripple. A hardware prototype is fabricated and tested. The Finite Element Analysis (FEA) software tool used for validating the test results is MagNet 7.6.0.8. Multi Objective Particle Swarm Optimization (MOPSO) is used to determine the various designs meeting the requirements of reduced torque ripple and improved torque performance. The results indicate the efficacy of the proposed methodology and substantiate the utilization of MOPSO as a significant tool for solving design problems related to SynRel motor.
\end{abstract}

Keywords: average torque, FEA, geometrical parameters, MOPSO, SynRel motor, torque ripple

\section{Introduction}

In recent times, Synchronous Reluctance (SynRel) Motors $[1,2]$ are establishing itself as an unique and significant technology, compared to conventional variable speed induction motor drives with the advent of effective control strategies, combined with aspects inclusive of high torque per volume, high torque per current, absence of magnets, thermally stable rotor and ease of maintenance. The applications include electric vehicle, traction, pumps and industrial fans.

Although SynRel motors have the above stated advantages, torque ripple can become pronounced and average torque may reduce with imprecise choice of geometrical parameters [3]. The presence of torque ripple might lead to undesirable vibration and noise and the reduction in average torque will decrease the efficiency of the motor. Meticulous efforts have been made in identifying the

(C)The Korean Magnetics Society. All rights reserved.

*Corresponding author: Tel: +91-9962626677

Fax:+91-44-27469772, e-mail: nagarajanvs@ssn.edu.in significant geometrical parameters contributing towards improving the performance of SynRel motor.

This work makes an effort in identifying the importance of the key geometrical parameters by determining and plotting average torque and torque ripple as contours [4] with respect to variation of the identified geometrical parameters in a structured fashion. This leads to the establishment of limits of geometrical parameters governing the best designs.

The noteworthy parameters influencing the performance of SynRel motor are present in the rotor which is anisotropic in construction with flux barriers. The parameters comprises of height of the barriers [3, 5-10], length of the barriers [5, 10], angular positions at air gap [3, 5-9], barrier tip angle [11, 12] and iron rib thickness $[3,13]$. Besides the above mentioned parameters, the effect of airgap and effect of skewing [3, 12] of rotor is analysed.

Finally, a two objective formulation with average torque and torque ripple percentage as the performance requirements is incepted with the optimization routine [14-18] performed using Multi Objective Particle Swarm Optimization (MOPSO) [19-22]. Surveying the literature, it is 
apparent that MOPSO not only boosts the convergence towards the true Pareto front but also produces a welldistributed Pareto front [21, 22]. Therefore, by the utilization of MOPSO, an attempt has been made to improve the performance of SynRel motor. The search space for the optimization algorithm is established using neural networks [22-25].

This paper is organized as follows. Section 2 deals with the hardware fabrication and experimental validation of the prototype motor using FEA software. In section 3, the individual effect of variations of geometrical parameters on performance parameters is analysed and the limits of significant geometrical parameters are framed. Section 4 describes optimization procedure along with the neural network based performance predictor. Conclusion is put forward in Section 5.

\section{Finite Element Model Validation}

The $1 / 8^{\text {th }}$ cross section of SynRel motor considered for analysis is shown in Fig. 1.

The geometrical parameters represented in Fig. 1 includes Heights of the barriers $\left(h_{b 1}, h_{b 2}, h_{b 3}\right)$, Length of the barriers $\left(l_{\mathrm{b} 1}, l_{\mathrm{b} 2}, l_{\mathrm{b} 3}\right)$, Angular positions at airgap, $\left(\Delta \delta_{1}\right.$, $\Delta \delta_{2}, \Delta \delta_{3}$ ) defined with respect to centre of the shaft, Flux barrier tip angles $\left(\beta_{1}, \beta_{2}, \beta_{3}\right)$ measured between the ends of the flux barriers, defined with respect to centre of the shaft, Iron rib thickness $\left(\mathrm{t}_{\mathrm{i}}\right)$, the thickness between the end of the flux barriers and periphery of the rotor and Air gap length $\left(\mathrm{a}_{\mathrm{g}}\right)$. The lamination of the prototype rotor used for analysis is based on significant contributions made in [3, 12, 26], and is shown in Fig. 2. The rotor was fabricated using Wire-cut Electrical Discharge Machining (EDM). The corresponding manufactured rotor is represented in

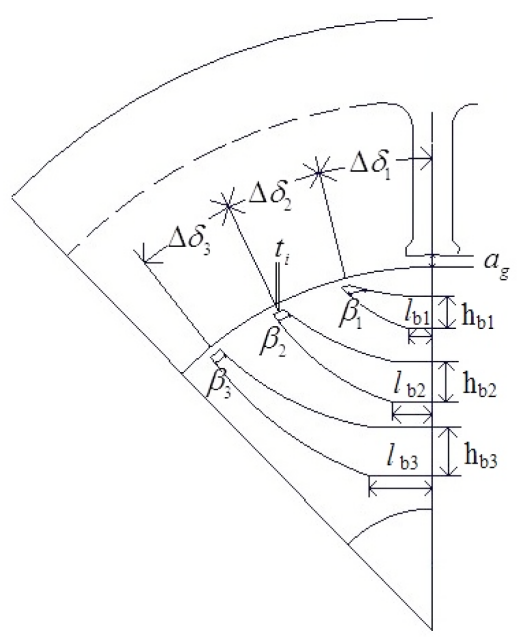

Fig. 1. Structure of cross section of SynRel motor.

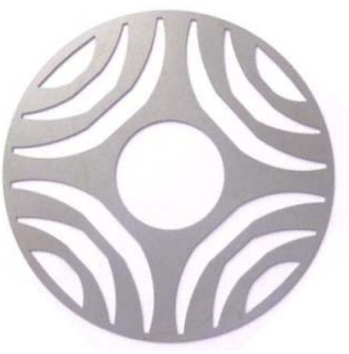

Fig. 2. (Color online) Lamination of SynRel rotor.

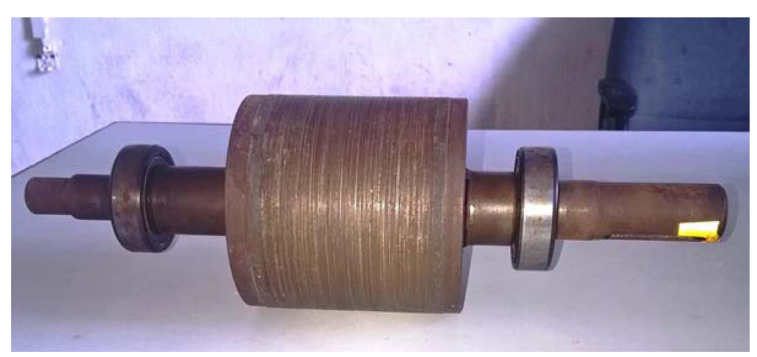

Fig. 3. (Color online) Rotor of SynRel motor.

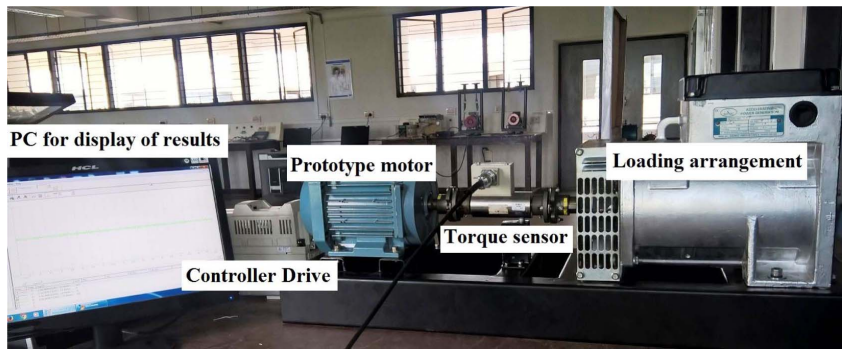

Fig. 4. (Color online) Experimental setup for obtaining torque response [27].

Fig. 3. The parameters of the manufactured prototype are listed in Table AI of appendix. The experimental setup for obtaining torque response is shown in Fig. 4. The experimental setup consists of torque sensor, prototype motor, loading arrangement consisting of generator and P-C for display of torque response.

The instantaneous torque curve obtained for the peak current from the experimental setup and Finite Element Analysis (FEA) [28-30], using MagNet 7.6.0.8 [31] is presented in Fig. 5. The solver details are specified in Table. AII of appendix. The torque ripple percentage is determined using

$$
T_{\text {ripple }} \%=\frac{T_{\max }-T_{\min }}{\text { Average torque }} \times 100
$$

Where analytical expression for average torque is given by [2]

$$
\text { Average torque, } T_{a v}=\frac{3}{2} \frac{p}{2}\left(L_{d}-L_{q}\right) I_{d} I_{q}
$$




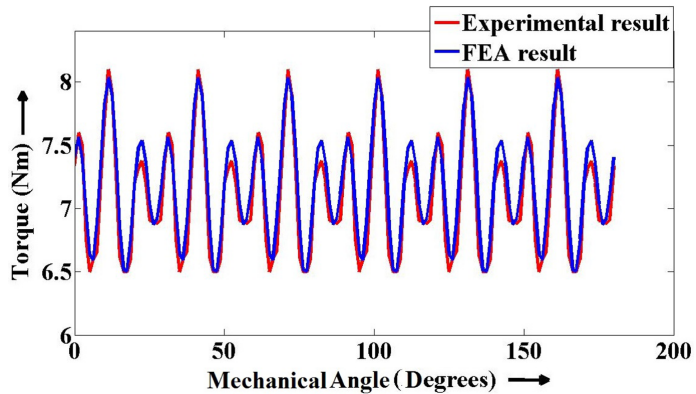

Fig. 5. (Color online) Torque response at rated current.

Table 1. Comparison between FEA and Experimental results.

\begin{tabular}{lcc}
\hline \multicolumn{1}{c}{ Performance parameter } & FEA results & Experimental result \\
\hline Average Torque $\left(\mathrm{T}_{\text {av }}\right)$ & $7.17 \mathrm{Nm}$ & $7.08 \mathrm{Nm}$ \\
$\begin{array}{l}\text { Torque ripple per-centage } \\
\left(\mathrm{T}_{\text {ripple }} \%\right)\end{array}$ & $21.327 \%$ & $22.580 \%$ \\
\hline
\end{tabular}

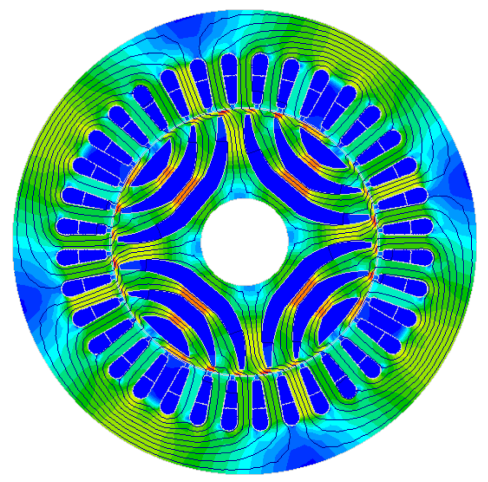

Fig. 6. (Color online) Flux pattern in SynRel motor.

$L_{d}, L_{q}: d$ axis and $q$ axis inductances

$I_{d}, I_{q}: d$ axis and $q$ axis currents

This work utilizes FEA results in the determination of the average torque.

The average torque and torque ripple percentage obtained from the experimental setup and FEA are represented in Table 1.

From Table 1 it is noted that there is a slight variation in the measured and simulated values, which may have arisen due to measurement errors. The observations indicate that FE model is suitable to predict the torque response of SynRel motor.

The corresponding flux pattern obtained using FEA analysis for the SynRel motor under analysis for peak current is represented in Fig. 6.

\section{Impact of Geometric Parameter Variations on Performance Parameters}

This section describes the influence on average torque

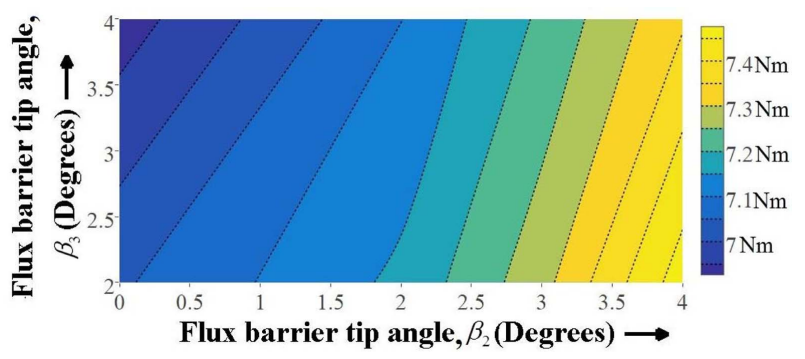

Fig. 7. (Color online) Influence of change of $\beta_{2}$ and $\beta_{3}$ with $\beta_{1}=2^{0}$ on average torque.

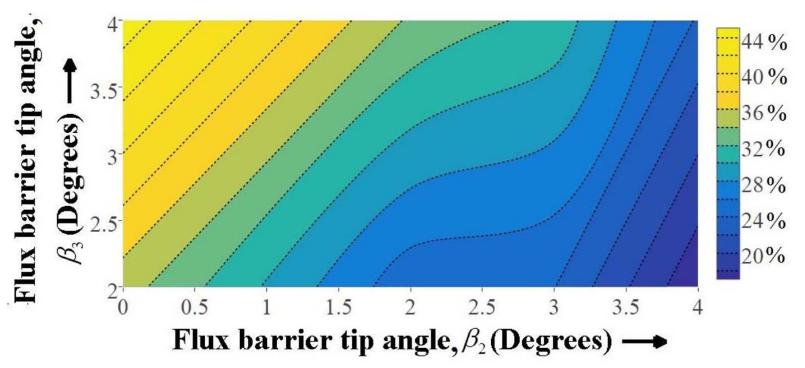

Fig. 8. (Color online) Influence of change of $\beta_{2}$ and $\beta_{3}$ with $\beta_{1}=2^{0}$ on torque ripple percentage.

and torque ripple with respect to variations of the geometrical parameters of SynRel motor. The intricacies involved in the design of SynRel motor are depicted by means of contour plots, with the parameters taking up the two axes and the performance parameter being represented by contours. The manufacturing process imposes the limits to the parameters. Eventually, the bounds of the parameters are established for the optimization routine.

\subsection{Influence of Flux barrier tip angles}

The flux barrier tip angles $[11,12]\left(\beta_{1}, \beta_{2}, \beta_{3}\right)$, describes the extent bounded by the flux barrier ends in degrees. Fig. 7 and Fig. 8 denote the substantial outcomes attained in obtaining average torque and torque ripple percentage, by the alteration of flux barrier tip angles, $\beta_{2}$ and $\beta_{3}$, when the flux barrier tip angle, $\beta_{1}$ was frozen at $2^{0}$.

From Fig. 7 and Fig. 8 , it is noticed that the average torque may increase till $7.4 \mathrm{Nm}$ and torque ripple percentage remains at $20 \%$ conforming to $\beta_{2}$ and $\beta_{3}$ taking up the values in the bounds of $3.5^{\circ}$ to $4^{0}$ and $2^{0}$ to $2.5^{0}$ respectively. But, the torque ripple percentage may increase upto $44 \%$ for $\beta_{2}=0^{0}$ and $\beta_{3}=4^{0}$. Similarly, the contour plot for variation of $\beta_{2}$ and $\beta_{3}$ with $\beta_{1}=6^{0}$ on average torque and torque ripple percentage is shown in Fig. 9 and Fig. 10 respectively.

Figure 9 and Fig. 10 signify that the average torque can be increased up to $7.5 \mathrm{Nm}$, but improper selection of $\beta_{1}$, $\beta_{2}$ and $\beta_{3}$ may shoot the torque ripple percentage to $40 \%$. 


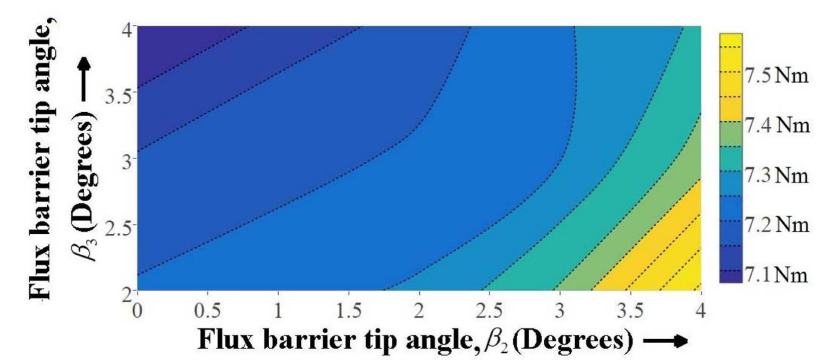

Fig. 9. (Color online) Influence of change of $\beta_{2}$ and $\beta_{3}$ with $\beta_{1}=6^{0}$ on average torque.

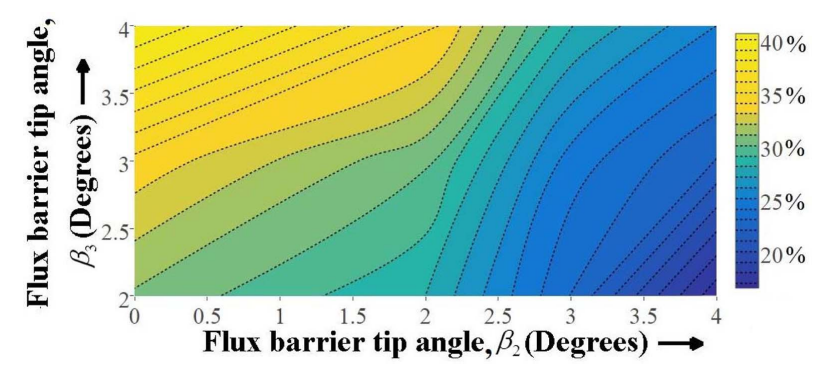

Fig. 10. (Color online) Influence of change of $\beta_{2}$ and $\beta_{3}$ with $\beta_{1}=6^{0}$ on torque ripple percentage.

\subsection{Influence of Angular positions at airgap}

The angular positions at airgap [3, 5-9] constitute the barrier limb locations for each rotor pole. The contour map for the influence of variation of $\Delta \delta_{1}$ and $\Delta \delta_{2}$ with $\Delta \delta_{3}$ $=8.5^{\circ}$ on average torque and torque ripple percentage is

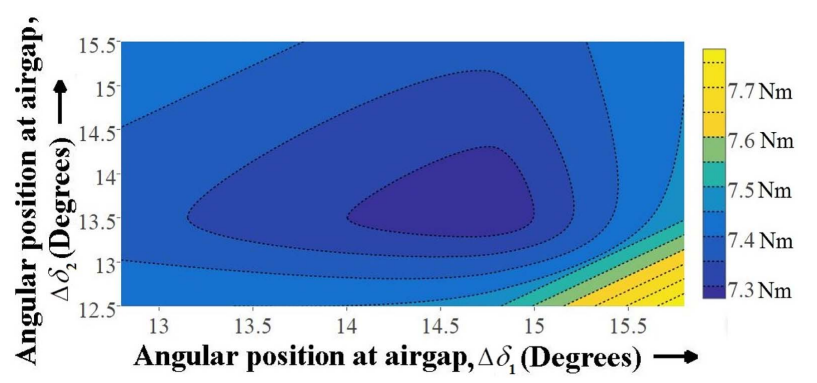

Fig. 11. (Color online) Influence of change of $\Delta \delta_{1}$ and $\Delta \delta_{2}$ with $\Delta \delta_{3}=8.5^{0}$ on average torque.

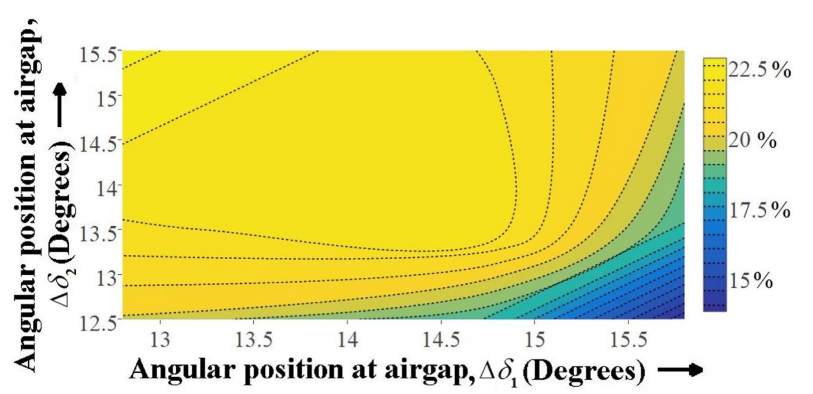

Fig. 12. (Color online) Influence of change of $\Delta \delta_{1}$ and $\Delta \delta_{2}$ with $\Delta \delta_{3}=8.5^{\circ}$ on torque ripple percentage.

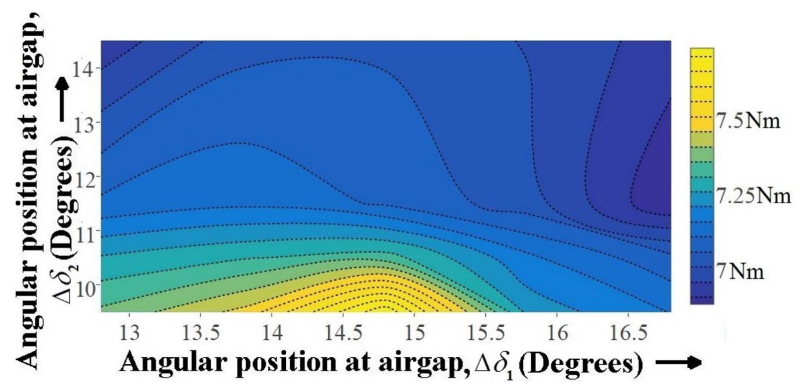

Fig. 13. (Color online) Influence of change of $\Delta \delta_{1}$ and $\Delta \delta_{2}$ with $\Delta \delta_{3}=12.5^{\circ}$ on average torque.

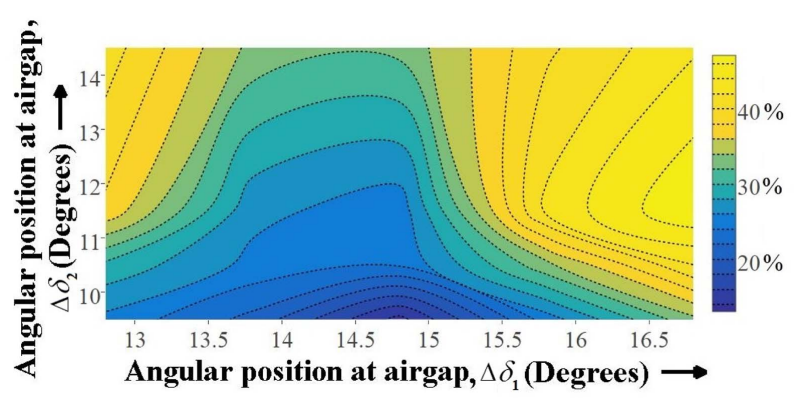

Fig. 14. (Color online) Influence of change of $\Delta \delta_{1}$ and $\Delta \delta_{2}$ with $\Delta \delta_{3}=12.5^{\circ}$ on torque ripple percentage.

shown in Fig. 11 and Fig. 12 respectively.

It is visualized that the average torque can be improvised till $7.7 \mathrm{Nm}$ and torque ripple percentage can be minimized till $15 \%$, corresponding to $\Delta \delta_{1}$ and $\Delta \delta_{2}$ in the bounds of $15^{0}$ to $16^{0}$ and $12.5^{0}$ to $13.5^{\circ}$. Similarly, corresponding to Fig. 13, the average torque can be increased above 7.5 $\mathrm{Nm}$, with $\Delta \delta_{1}$ and $\Delta \delta_{2}$ in the range of $14^{\circ}$ to $15.5^{\circ}$ and $9.5^{\circ}$ to $10.5^{0}$.

From Fig. 14, it can be proved that torque ripple percentage may go beyond $40 \%$ with improper choice of $\Delta \delta_{1}, \Delta \delta_{2}$ and $\Delta \delta_{3}$. In Fig. 15 , it can be seen that the torque ripple percentage can be minimized up to $12 \%$.

\subsection{Influence of Airgap and Iron rib thickness}

Concurrent modification of air gap $\left(\mathrm{a}_{\mathrm{g}}\right)[3,5-9]$ and iron

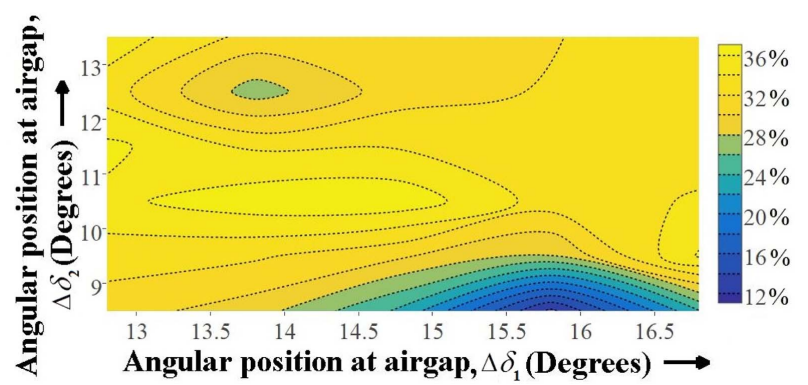

Fig. 15. (Color online) Influence of change of $\Delta \delta_{1}$ and $\Delta \delta_{2}$ with $\Delta \delta_{3}=14.5^{0}$ on torque ripple percentage. 


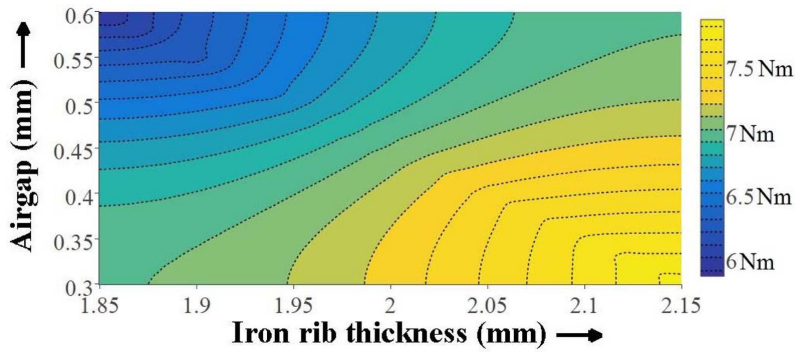

Fig. 16. (Color online) Influence of change of $t_{i}$ and $a_{g}$ on average torque.

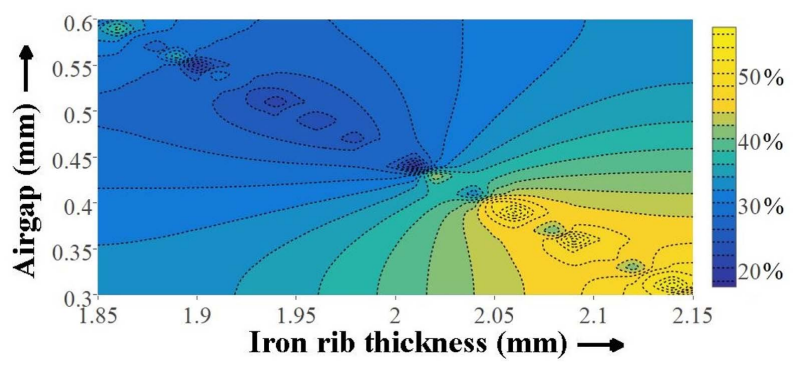

Fig. 17. (Color online) Influence of change of $t_{i}$ and $a_{g}$ on torque ripple percentage.

rib thickness $\left(t_{i}\right)[3,13]$ are performed. The bound of alteration of airgap is from 0.3 to $0.6 \mathrm{~mm}$. The iron rib thickness is varied between $1.85 \mathrm{~mm}$ and $2.15 \mathrm{~mm}$. Usually, smaller values of iron rib thickness $\left(t_{i}\right)$ lead to minimization in torque ripple [13]. The specified bound is carefully chosen to maintain the rigidity of rotor. Fig. 16 and Fig. 17 details the effect of variation of airgap and iron rib thickness concurrently, on average torque and torque ripple percentage.

From Fig. 16 and Fig. 17, it is perceived that a rise in iron rib thickness beyond $2 \mathrm{~mm}$ and reduction in air gap in the bound of 0.4 and $0.3 \mathrm{~mm}$ will lead to rise in the torque ripple percentage above $50 \%$, although average torque escalates to $8.5 \mathrm{Nm}$. The susceptibility of airgap and iron rib thickness towards torque ripple percentage can be evidently pictured from Fig. 16 and Fig. 17. It is also perceived that optimal possibilities of airgap in the bound of 0.4 to $0.55 \mathrm{~mm}$ will be sufficient in realizing reduced torque ripple percentage, with iron rib thickness frozen towards $2 \mathrm{~mm}$.

\subsection{Influence of Height of the barriers}

The heights of the barriers [3,5-10] $\left(h_{b 1}, h_{b 2}, h_{b 3}\right)$, are varied with the logic that the heights of the barriers shall be greater than or equal to subsequent barrier heights when proceeding from shaft to rotor periphery. Fig. 18 and Fig. 19 indicate the change of $h_{b 2}$ and $h_{b 3}$ on average torque and torque ripple percentage with $h_{b 1}$ kept at 3

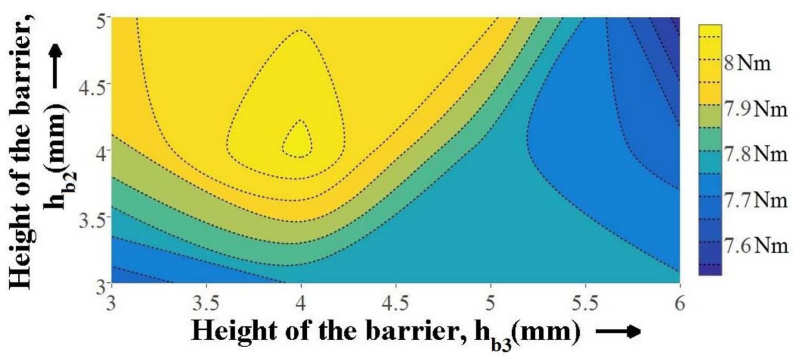

Fig. 18. (Color online) Influence of change of $h_{b 2}$ and $h_{b 3}$, for $\mathrm{h}_{\mathrm{b} 1}=3 \mathrm{~mm}$ on average torque.

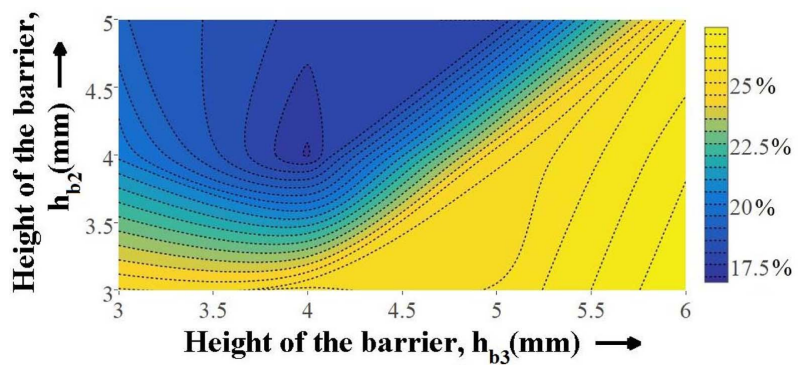

Fig. 19. (Color online) Influence of change of $h_{b 2}$ and $h_{b 3}$, for $\mathrm{h}_{\mathrm{b} 1}=3 \mathrm{~mm}$ on torque ripple percentage.

$\mathrm{mm}$.

From Fig. 18 and Fig. 19, it can be witnessed that the average torque can be increased till $8 \mathrm{Nm}$ and torque ripple percentage reduced to $17.5 \%$ with $h_{b 2}$ and $h_{b 3}$ in the bound of $3.5 \mathrm{~mm}$ to $5.2 \mathrm{~mm}$. Similar observations can

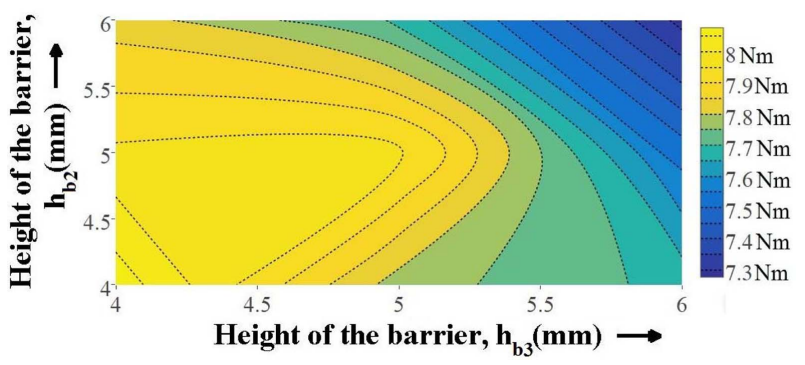

Fig. 20. (Color online) Influence of change of $h_{b 2}$ and $h_{b 3}$, for $\mathrm{h}_{\mathrm{b} 1}=4 \mathrm{~mm}$ on average torque.

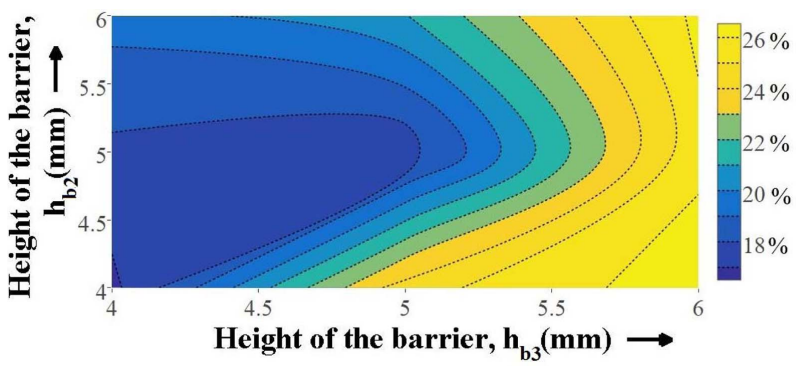

Fig. 21. (Color online) Influence of change of $h_{b 2}$ and $h_{b 3}$, for $\mathrm{h}_{\mathrm{b} 1}=4 \mathrm{~mm}$ on torque ripple percentage. 


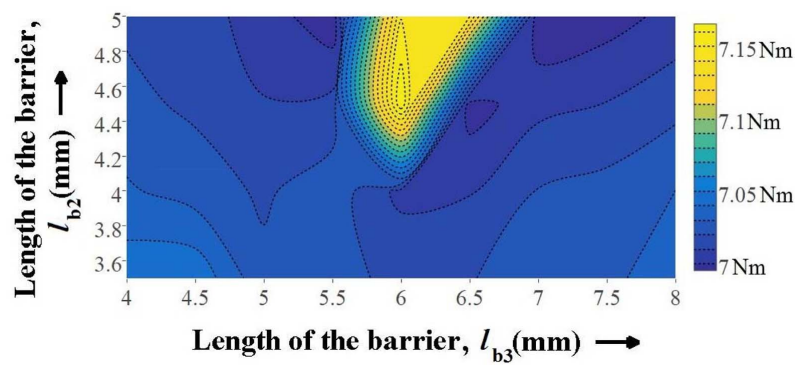

Fig. 22. (Color online) Influence of change of $l_{\mathrm{b} 2}$ and $l_{\mathrm{b} 3}$, for $l_{\mathrm{b} 1}=3 \mathrm{~mm}$ on average torque.

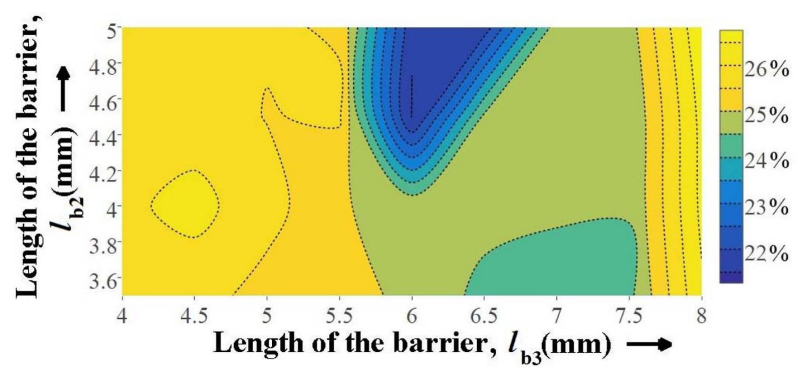

Fig. 23. (Color online) Influence of change of $l_{\mathrm{b} 2}$ and $l_{\mathrm{b} 3}$, for $l_{\mathrm{b} 1}=3 \mathrm{~mm}$ on torque ripple percentage.

be deduced from Fig. 20 and Fig. 21, with the average torque rise till $8 \mathrm{Nm}$ and torque ripple percentage reduction till $18 \%$.

\subsection{Influence of Length of the barriers}

The lengths of the barriers $[5,10]\left(l_{\mathrm{b} 1}, l_{\mathrm{b} 2}, l_{\mathrm{b} 3}\right)$, are varied with the conception that the lengths of the barriers shall be greater than or equal to subsequent barrier lengths when proceeding from shaft to rotor periphery. Fig. 22 and Fig. 23 indicate the change of $l_{\mathrm{b} 2}$ and $l_{\mathrm{b} 3}$ on average torque and torque ripple percentage with $l_{\mathrm{b} 1}$ kept at $3 \mathrm{~mm}$.

From Fig. 22 and Fig. 23, it is witnessed that the average torque does not increase considerably when the length of the barrier is changed. There is no noteworthy decline in torque ripple percentage too. Nevertheless, the length of the barrier is a vital feature, when it is associated with the height of the barrier in increasing the average torque and reducing the torque ripple percentage. The lengths of the barriers $l_{\mathrm{b} 1}=3 \mathrm{~mm}, l_{\mathrm{b} 2}=5 \mathrm{~mm}$ and $l_{\mathrm{b} 3}=$ $8 \mathrm{~mm}$, were directed to lessening of torque ripple percentage and improvisation in average torque when the heights of the barriers were changed. An inappropriate selection of length of barrier may cause the torque ripple percentage rise up to $26 \%$.

\subsection{Influence of skewing of rotor}

The influence of skewing in rotor is studied in $[3,12]$.

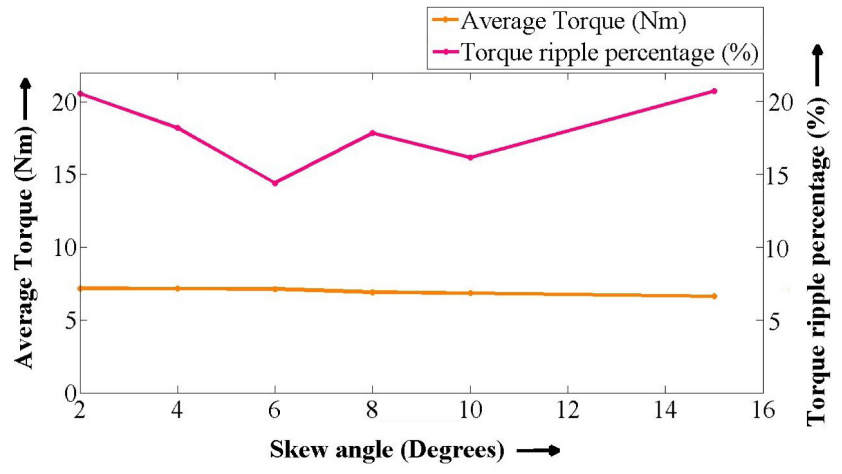

Fig. 24. (Color online) Effect of skew angle of rotor on average torque and torque ripple percentage.

The outcome of skewing is studied again, to verify its necessity in optimization process.

In Fig. 24, it is visualized that even if torque ripple percentage is decreased by skewing for certain angles, the average torque reduces considerably. Besides, skewing of rotor is a complex procedure in fabrication of the rotor, which need not be entertained for the design of SynRel motor.

From the influence of distinctive alterations in geometrical parameters, it is noted that the average torque can be raised up to $8 \mathrm{Nm}$ and torque ripple percentage can be minimized to $12 \%$. However, an optimization process has to be formulated to study the significant parametric influence on average torque and torque ripple percentage. The bounds of the parameters are selected and represented in Table 2, depending on the substantial results achieved in the subcategories put forward earlier.

Table 2. Lower and upper bounds of geometrical parameters for optimization routine.

\begin{tabular}{cccc}
\hline \hline Parameter & Symbol & $\begin{array}{c}\text { Lower } \\
\text { bound }\end{array}$ & $\begin{array}{c}\text { Upper } \\
\text { bound }\end{array}$ \\
\hline Height of the & $\mathrm{h}_{\mathrm{b} 1}$ & $3 \mathrm{~mm}$ & $4 \mathrm{~mm}$ \\
barrier & $\mathrm{h}_{\mathrm{b} 2}$ & $3.5 \mathrm{~mm}$ & $5.2 \mathrm{~mm}$ \\
& $\mathrm{~h}_{\mathrm{b} 3}$ & $3.5 \mathrm{~mm}$ & $6 \mathrm{~mm}$ \\
\hline \multirow{2}{*}{ Length of the } & $l_{\mathrm{b} 1}$ & $2 \mathrm{~mm}$ & $3.5 \mathrm{~mm}$ \\
barrier & $l_{\mathrm{b} 2}$ & $3 \mathrm{~mm}$ & $5 \mathrm{~mm}$ \\
& $l_{\mathrm{b} 3}$ & $5 \mathrm{~mm}$ & $7 \mathrm{~mm}$ \\
\hline \multirow{2}{*}{ Angularpositions } & $\Delta \delta_{1}$ & $11.5^{0}$ & $16^{0}$ \\
at the air gap & $\Delta \delta_{2}$ & $8.5^{0}$ & $13.5^{0}$ \\
\hline \multirow{2}{*}{ Flux barrier tip } & $\Delta \delta_{3}$ & $8.5^{0}$ & $14.5^{0}$ \\
angles & $\beta_{1}$ & $0^{0}$ & $6^{0}$ \\
\hline Airgap & $\beta_{2}$ & $1^{0}$ & $4^{0}$ \\
\hline & $\beta_{3}$ & $0^{0}$ & $3^{0}$ \\
\hline
\end{tabular}




\section{Optimization Routine using MOPSO}

PSO is a potent stochastic optimization procedure [19, 20] established on the transit and intellect of hordes developed by Kennedy and Eberhart in 1995. The idea behind PSO is in accelerating every particle toward its pbest (best fitness achieved by the particle) and gbest (best fitness achieved by any particle), with a random weighted acceleration at each instant.

The formulation of optimization problem is defined in Eqn. (3) and Eqn. (4).

Minimization of torque ripple percentage,

$f_{1}=\min \left(T_{\text {ripple }} \%\right)$

Maximization of average torque,

$f_{2}=\max \left(T_{a v}\right)$

\subsection{ANN based performance prediction}

Optimization procedure includes computation of average torque and torque ripple for every set of input in the design field. Yet for all sets of input, the calculation of performance parameters by FEA requires substantial interval of time and might prolong the optimization routine. In order to minimize this, a feed forward neural network is trained with distinct set of points in the design field. 145 designs are considered using FEA [28-30], to train the neural network [22-25], for determining the average torque and torque ripple with respect to the geometrical parameters, represented in Fig. 25. The trained neural network is utilized to produce the required data for every

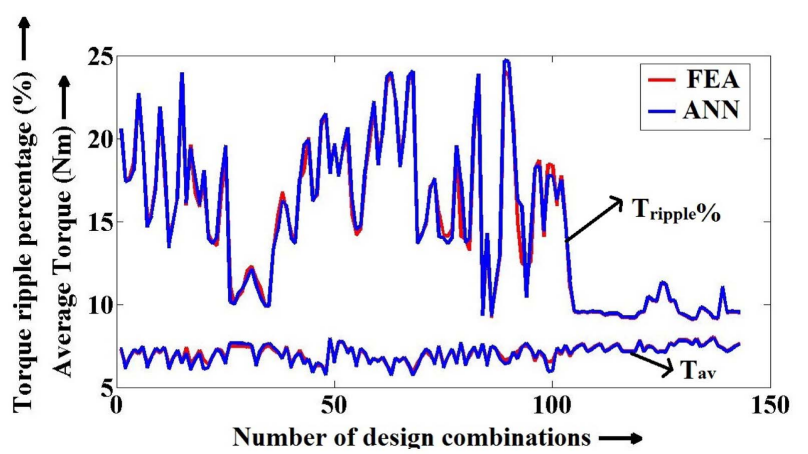

Fig. 25. (Color online) Comparison between ANN and FEA results for various design combinations.

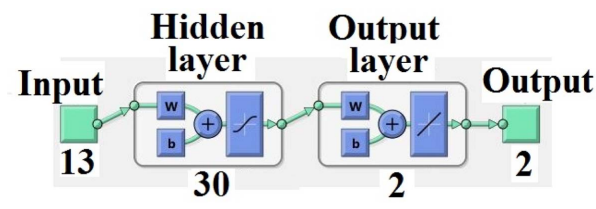

Fig. 26. (Color online) Structure of the neural network. set of input through the optimization procedure. The geometrical parameters constitute the input to the neural network and the outputs obtained are average torque and torque ripple percentage. In this study feed forward neural network is made use of with sigmoid activation function, for the evaluation of average torque and torque ripple percentage. The neural network is trained by Back Propagation Algorithm. The structure of the neural network is shown in Fig. 26.

\subsection{Optimization procedure}

The mathematical representations [22] involved with the single objective PSO is represented as follows.

The position is given by $X_{i}=\left[X_{i 1}, X_{i 2} \ldots X_{i n}\right]$ and the velocity is given by $V_{i}=\left[V_{i 1}, V_{i 2} \ldots V_{i n}\right]$ in the search space $N$.

The velocity of every particle in the subsequent iteration is determined by

$$
\begin{aligned}
V_{i, n}^{k+1}= & w V_{i, n}^{k}+c_{1} \operatorname{rand}_{1}\left(\text { pbest }_{i, n}-X_{i, n}^{k}\right) \\
& +c_{2} \text { rand }_{2}\left(\text { pbest }_{n}-X_{i, n}^{k}\right)
\end{aligned}
$$

where $i=1,2, \ldots, m ; n=1,2, \ldots, N ; \mathrm{m}$ is the number of particles in the swarm and $N$ is the number of dimensions in a particle.

The position of the particle is updated by the following equations

$$
\begin{aligned}
& X_{i, n}^{k+1}=X_{i, n}^{k}+V_{i, n}^{k+1} \text { if } X_{\min , i, n} \leq X_{i, n}^{k+1} \leq X_{\max , i, n} \\
& X_{i, n}^{k+1}=X_{\min , i, n} \text { if } X_{i, n}^{K+1}>X_{\min , i, n} \\
& X_{i, n}^{k+1}=X_{\max , i, n} \text { if } X_{i, n}^{K+1}>X_{\max , i, n}
\end{aligned}
$$

where $\mathrm{k}$ is the number of iterations, $X_{i, n}^{k}$ and $V_{i, n}^{k}$ denote the current position and velocity of the particle $i$ at iteration $k$.

The velocity update for the $i^{\text {th }}$ particle [21], when the non-dominated solutions are to be selected in the archive subdivided into hypercubes is given by

$$
\begin{aligned}
V_{i}(k+1)= & w V_{i}(k)+c_{1} \operatorname{rand}_{1}\left(\text { pbest }_{i}(k)-X_{i}(k)\right) \\
& +c_{2} \operatorname{rand}_{2}\left(R_{h}(k)-X_{i}(k)\right)
\end{aligned}
$$

where pbest $_{i}$ refers to its best position, $X_{i}$ is the current position, $R_{h}$ is the selected particle from the repository, $w$ is the weighting factor, $c_{1}$ and $c_{2}$ are the acceleration factors, rand $_{1}$ and $\mathrm{rand}_{2}$ are random numbers between 0 and $1, k$ refers to the pointer of iterations (generations).

The flowchart for the optimization routine is represented in Fig. 27.

\subsection{Results}

The MOPSO algorithm has been implemented using 


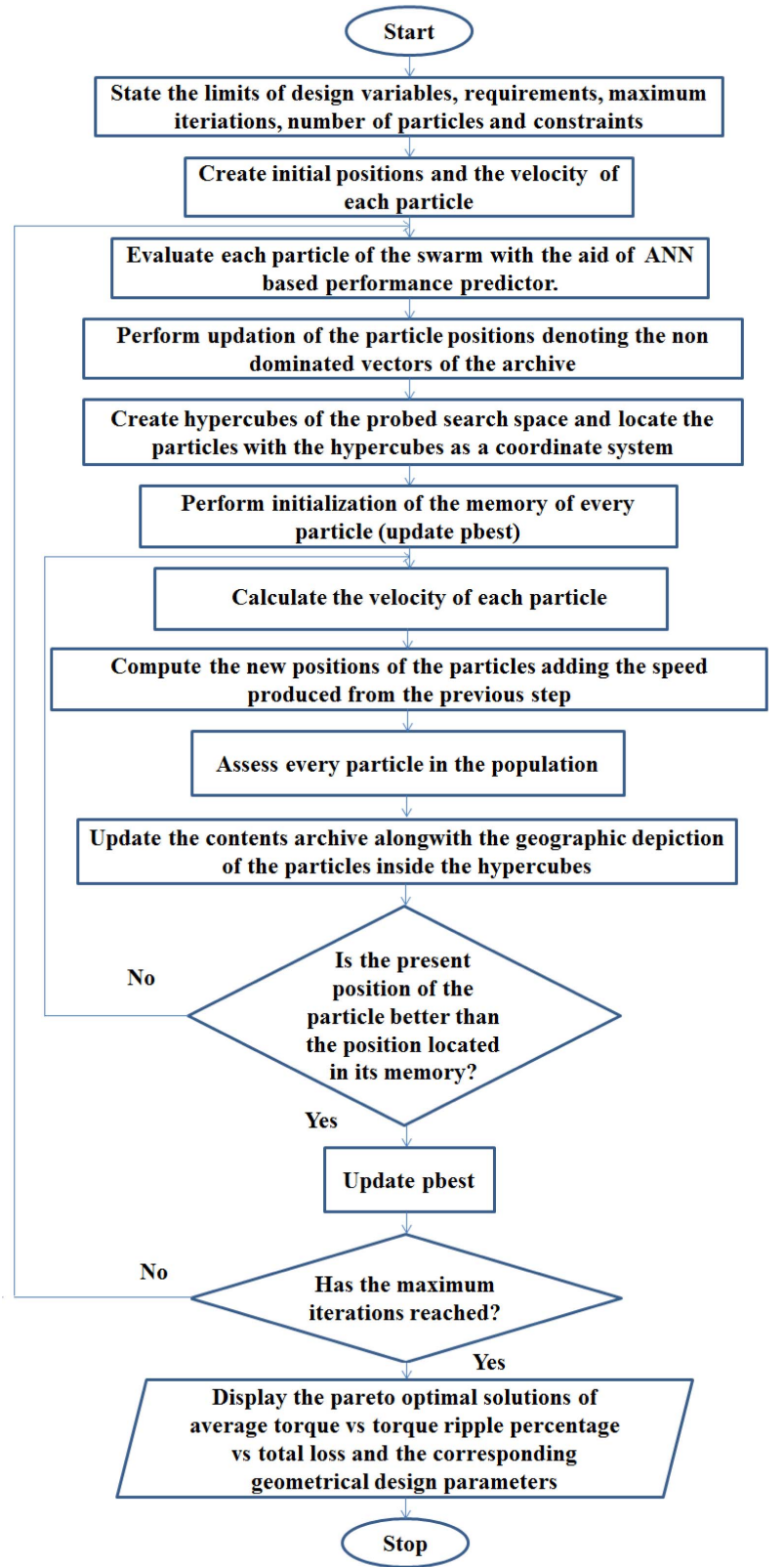

Fig. 27. (Color online) Flowchart for MOPSO optimization procedure.

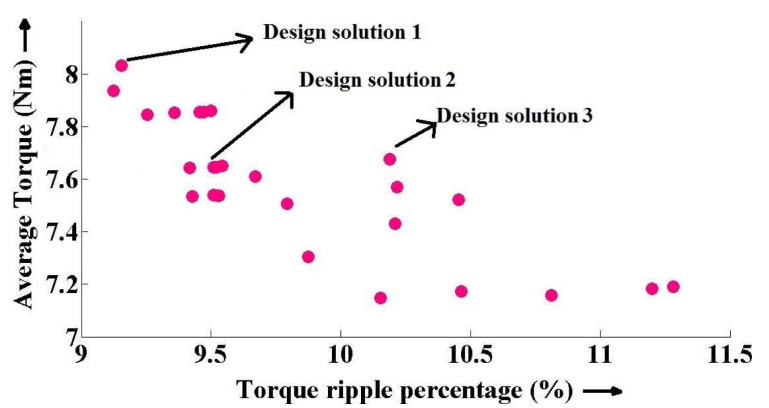

Fig. 28. (Color online) Results of MOPSO optimization routine.
Table 3. Distinctive solutions of the optimization routine.

\begin{tabular}{ccccc}
\hline \hline \multirow{2}{*}{ Parameter } & \multicolumn{4}{c}{ Design solutions } \\
& Symbol & Design & Design & Design \\
& & 1 & 2 & 3 \\
\hline \multirow{3}{*}{ Heights of barriers } & $\mathrm{h}_{\mathrm{b} 1}$ & $3 \mathrm{~mm}$ & $3.5 \mathrm{~mm}$ & $3 \mathrm{~mm}$ \\
& $\mathrm{~h}_{\mathrm{b} 2}$ & $4.2 \mathrm{~mm}$ & $4.7 \mathrm{~mm}$ & $4.3 \mathrm{~mm}$ \\
& $\mathrm{~h}_{\mathrm{b} 3}$ & $5.2 \mathrm{~mm}$ & $5.9 \mathrm{~mm}$ & $5.4 \mathrm{~mm}$ \\
\hline \multirow{3}{*}{ Length of barriers } & $l_{\mathrm{b} 1}$ & $3 \mathrm{~mm}$ & $3 \mathrm{~mm}$ & $2 \mathrm{~mm}$ \\
& $l_{\mathrm{b} 2}$ & $4.5 \mathrm{~mm}$ & $4.5 \mathrm{~mm}$ & $3 \mathrm{~mm}$ \\
& $l_{\mathrm{b} 3}$ & $6.7 \mathrm{~mm}$ & $6 \mathrm{~mm}$ & $5 \mathrm{~mm}$ \\
\hline \multirow{2}{*}{ Angular positions } & $\Delta \delta_{1}$ & $12.4^{0}$ & $11.5^{0}$ & $12.6^{0}$ \\
at the air gap & $\Delta \delta_{2}$ & $12.8^{0}$ & $13.5^{0}$ & $12.9^{0}$ \\
& $\Delta \delta_{3}$ & $13.2^{0}$ & $13^{0}$ & $13^{0}$ \\
\hline \multirow{2}{*}{ Flux barrier tip } & $\beta_{1}$ & $3.3^{0}$ & $5^{0}$ & $3.2^{0}$ \\
angles & $\beta_{2}$ & $1.8^{0}$ & $2.3^{0}$ & $1.7^{0}$ \\
& $\beta_{3}$ & $1.3^{0}$ & $2^{0}$ & $1.4^{0}$ \\
\hline Airgap & $\mathrm{a}_{\mathrm{g}}$ & $0.47 \mathrm{~mm}$ & $0.51 \mathrm{~mm}$ & $0.51 \mathrm{~mm}$ \\
\hline Average Torque & $\mathrm{T}_{\mathrm{av}}$ & $8.03 \mathrm{Nm}$ & $7.67 \mathrm{Nm}$ & $7.64 \mathrm{Nm}$ \\
\hline Torque ripple & $\mathrm{T}_{\mathrm{ripple}}$ & $9.153 \%$ & $10.189 \%$ & $9.509 \%$ \\
percentage & $\%$ & & & \\
\hline Total Loss & $\mathrm{P}_{\text {loss }}$ & $119.13 \mathrm{~W}$ & $114.58 \mathrm{~W}$ & $115.50 \mathrm{~W}$ \\
\hline & & & &
\end{tabular}

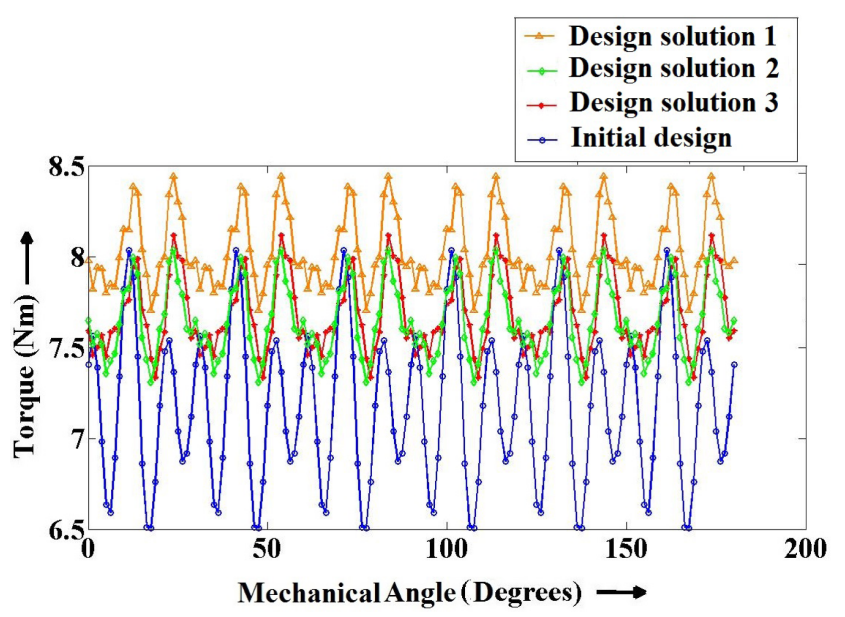

Fig. 29. (Color online) Torque response of three design solutions compared with the initial design.

MATLAB [32], with the population (swarm) size $=100$ particles, $c_{1}=1.5, c_{2}=1.5, w=0.5$, size of archive $=100$ and maximum number of iterations $=150$. The results of optimization are represented in Fig. 28.

Three noteworthy solutions in view of the torque ripple minimization and their corresponding loss values have been represented in Table. 3 .

The torque response curves corresponding to the three design solutions and initial design are represented in Fig. 29. 


\section{Conclusion}

The influence of geometrical parameter variations of SynRel motor on torque ripple and average torque were explored in detail. The limits of significant geometrical parameters were established from the analysis performed, giving a guideline in the choice of parameters. An optimization procedure using MOPSO was executed, which is found appropriate to improve the performance of the SynRel motor. The thermal and vibration analysis for the optimized designs form the future scope of the work.

\section{Acknowledgement}

This research was supported and funded by Department of Science and Technology, Government of India and SSN Trust.

\section{References}

[1] Boldea, Reluctance Synchronous Machines and Drives, Clarendon press (1996).

[2] T. Lipo, Electric Machines \& Power Systems 19, 659 (1991).

[3] N. Bianchi, M. Degano, and E. Fornasiero, IEEE Trans. Ind. Appl. 51, 187 (2015).

[4] M. H. Yoon, D. Y. Kim, S. I. Kim, and J. P. Hong, J. Magn. 20, 387 (2015).

[5] R. R. Moghaddham, Master's Thesis, KTH University, Sweden (2007).

[6] R. R. Moghaddam and F. Gyllensten, IEEE Trans. Ind. Appl. 61, 5058 (2014).

[7] G. Pellegrino, F. Cupertino, and C. Gerada, IEEE Trans. Ind. Appl. 51, 1465 (2015).

[8] F. Cupertino, G. Pellegrino, and C. Gerada, IEEE Trans. Ind. App. 50, 3617 (2014).

[9] M. Gamba, G. Pelegrino, and F. Cupertino, ICEM, Berlin 1334 (2014).

[10] K. S. Khan, Master Thesis, KTH University, Sweden (2011).

[11] K. Wang, Z. Q. Zhu, G. Ombach, M. Koch, S. Zhang, and J. Xu COMPEL 34, 18 (2015).

[12] E. Howard, M. J. Kamper, and S. Gerber, IEEE Trans. Ind. Appl. 51, 3751 (2015).

[13] S. Taghavi and P. Pillay, ECCE, 5131 (2014).

[14] K. Deb, Multi-Objective Optimization using Evolutionary Algorithms Wiley, Singapore (2001).

[15] P. Di Barba, Multiobjective Shape Design in Electricity and Magnetism, Springer (2010).

[16] S. H. Kam and T. U. Jung, J. Magn. 20, 91 (2015).

[17] M. Yaxdani-Asrami, M. Alipour, and S. Asghar Gholamian, J. Magn. 20, 161 (2015).

[18] J. Baek, S. Kwak, and H. A. Toliyat, J. Magn. 18, 65
(2013).

[19] R. Eberhart and J. Kennedy, MHS 43 (1995).

[20] J. Kennedy and R. Eberhart, ICNN 4, 1948 (1995).

[21] C. A. C. Coello, G. T. Pulido, and M. S. Lechuga, IEEE Trans. Evol. Comput. 8, 279 (2004).

[22] N. Umadevi, M. Balaji V. Kamaraj, and L. Ananda Padmanaban, COMPEL 34, 1318 (2015).

[23] H. Sahraoui, H. Zeroug, and H. A. Toliyat, IEEE Trans. Magn. 43, 4095 (2007).

[24] W. Yan, IEEE Trans. Neural Netw. Learn. Syst. 23, 1039 (2012).

[25] M. Balaji and V. Kamaraj, JEPE, 63 (2012).

[26] K. Wang, Z. Q. Zhu, G. Ombach, M. Koch, S. Zhang, and J. Xu, J. Magn. 34, 3 (2015).

[27] S. A. Hong, J. Y. Choi, and S. M. Jang, J. Magn. 19, 84 (2014).

[28] S. H. Lee, Y. J. Kim, K. S. Lee, and S. J. Kim, J. Magn. 20, 444 (2015).

[29] J. H. Lee and I. K. Lee, J. Magn. 15, 85 (2010).

[30] J. H. Lee and A. R. Jeon, J. Magn. 15, 138 (2010).

[31] http://www.infolytica.com

[32] http://www.mathworks.com

\section{Appendix}

Table AI. Parameters of prototype SynRel motor.

\begin{tabular}{lc}
\hline \hline Parameter & Value \\
\hline Rated power & $1.1 \mathrm{~kW}$ \\
Rated Speed & $1500 \mathrm{rpm}$ \\
Rated current & $2.9 \mathrm{~A}$ \\
Number of phases & 3 \\
Number of poles & 4 \\
Number of stator slots & 36 \\
Air gap & $0.45 \mathrm{~mm}$ \\
Diameter of rotor & $91.2 \mathrm{~mm}$ \\
Inner diameter of stator & $92.1 \mathrm{~mm}$ \\
Outer diameter of stator & $159 \mathrm{~mm}$ \\
Stack length & $64 \mathrm{~mm}$ \\
Shaft diameter & $30 \mathrm{~mm}$ \\
Height of barrier, $\mathrm{h}_{\mathrm{b} 1}$ & $6 \mathrm{~mm}$ \\
Height of barrier, $\mathrm{h}_{\mathrm{b} 2}$ & $6 \mathrm{~mm}$ \\
Height of barrier, $\mathrm{h}_{\mathrm{b} 3}$ & $6 \mathrm{~mm}$ \\
Length of barrier, $l_{\mathrm{b} 1}$ & $3 \mathrm{~mm}$ \\
Length of barrier, $l_{\mathrm{b} 2}$ & $5 \mathrm{~mm}$ \\
Length of barrier, $l_{\mathrm{b} 3}$ & $8 \mathrm{~mm}$ \\
Angular position at the air gap, $\Delta \delta_{1}$ & $14.8^{0}$ \\
Angular position at the air gap, $\Delta \delta_{1}$ & $11.5^{0}$ \\
Angular position at the air gap, $\Delta \delta_{1}$ & $12.5^{0}$ \\
Flux barrier tip angle, $\beta_{1}$ & $0^{0}$ \\
Flux barrier tip angle, $\beta_{1}$ & $1.9^{0}$ \\
Flux barrier tip angle, $\beta_{1}$ & $2.1^{0}$ \\
Iron rib thickness, $\mathrm{t}_{\mathrm{i}}$ & $2 \mathrm{~mm}$ \\
Total Loss & $113.44 \mathrm{~W}$ \\
\hline
\end{tabular}


Table AII. Solver details.

\begin{tabular}{lc}
\hline \multicolumn{1}{c}{ Parameter } & Value \\
\hline Meshing type & Planar triangular meshing \\
Meshing tolerance & $1.113 \mathrm{e}-007$ \\
Number of triangles & 41606 \\
Degree of freedom & 20836 \\
Conjugate gradient tolerance & 0.0001 \\
Newton tolerance & 0.01 \\
\hline
\end{tabular}

